NASA Technical Memorandum 86439

NASA-TM-86439 19850022699

TRANSONIC CALCULATIONS FOR A FLEXIBLE SUPERCRITICAL WING AND COMPARISON WITH EXPERIMENT

ROBERT M. BENNETT

DAVID A. SEIDEL

MAYNARD C, SANDFORD

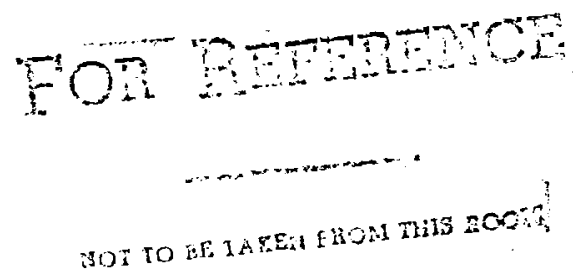

MAY 1985

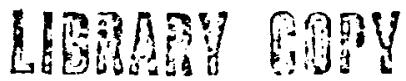 \\ .j. $9: 3005$}

LANGLEY FESENTIFH CEYUTER

LIZRAXY, NASA

HE...PTOIS, VIRGII:A 


\title{
TRANSONIC CALCULATIONS FOR A FLEXIBLE SUPERCRITICAL WING AND COMPARISON WITH EXPERIMENT
}

\author{
Robert M. Bennett and David A. Seidel \\ Unsteady Aerodynamics Branch \\ Loads and Aeroelasticity Division
}

and

Maynard C. Sandford Configuration Aeroelasticity Branch Loads and Aeroelasticity Division

NASA Langley Research Center Hampton, Virginia 23665

\section{Abstract}

Pressure data measured on the flexible DAST ARW-2 wing are compared with results calculated using the transonic small perturbation code XTRAN3S. A brief description of the analys is is given and a recently-developed grid coordinate transformation is described. Calculations are presented for the rigid and flexible wing for Mach numbers from 0.60 to 0.90 and dynamic pressures from 0 to 1000 psf. Calculated and measured static pressures and wing deflections are compared, and calculated static aeroelastic trends are given. Attempts to calculate the transonic instability boundary of the wing are described.

\section{Nomenclature}

c airfoll chord, in

$C_{L} \quad$ wing lift coefficient

$C_{M} \quad$ wing pitching moment coefficient

about the wing root leading edge

$C_{p} \quad$ pressure coefficient

$\hat{C}_{p} \quad$ critical pressure coefficient

$c_{r} \quad$ wing reference chord, in

ON value at downstream boundary of finite

difference grid

LE $\quad$ leading edge value

$O B$ value at far spanwise boundary of

finite difference grid

$q$ dynamic pressure, psf

$r$ function defining instantaneous

position of wing surface, $z=r(x, y, t)$

$t$ time, sec

TE trailing edge value

TIP wing tip-value

UP value at upstream boundary of finite difference grid

$V \quad$ free stream velocity, in/sec

$x, y, z$ coordinates of a right hand Cartesian system with origin at wing root leading edge, positive $x$ in downstream direction, $y$ in spanwise direction, and $z$ up, in

zt wing-tip displacement, in

$\alpha$ wing root angle of attack, degrees

$\gamma \quad$ ratio of specific heats

$\bar{n} \quad$ fraction of semispan

$\theta_{t} \quad$ wing-tip rotation, positive leading edge up, degrees

\author{
$\xi, n, \xi$ transformed coordinates in $x, y$, and $z$ \\ directions respectively \\ $\rho$ density, slugs/ft 3 \\ $\tau$ transformed time, $\tau=t$ \\ perturbation velocity potential
}

\section{Introduction}

The transonic speed range is a critical region for many aeroelastic phenomena such as flutter and divergence. In the past, analytical methods have been unable to predict accurately the nonlinear transonic aerodynamics and analysts have used linear theory for estimates of transonic aeroelastic behavior. Reliance was placed primarily on tests of scaled aeroelastic models and on flight tests of prototype aircraft for flutter clearance and aeroelastic deformation effects. Recently, considerable progress has been made in calculating steady transonic flows about aircraft using finite difference methods to obtain numerical solutions of the flow equations. Significant progress also is being made toward developing finite difference methods for unsteady flows which eventually may lead to accurate transonic aeroelastic analyses.

For two-dimensional flows, methods based on the transonic small perturbation (TSP) equation have been developed and extensively applied (see ref. 1-2 for example). These methods have been extended to include viscous effects, ${ }^{3}, 4$ nonisentropic effects," and wing-canard configurations. ${ }^{\circ}$ For three-dimensional flows, the XTRAN3S program has been developed" by the Boeing Company under USAF contract. It treats an isolated planar wing including aeroelastic deformation effects and unsteady motion. The XTRAN3S program has been implemented on the Control Data Corporation VPS 32 computer at the NASA Langley Research Center. A variety of applications are being made in order to evaluate its applicability to several types of wings.

Several organizations have expended significant effort to measure static and oscillatory pressures on wings at transonic speeds for use in evaluating computational methods and to improve the understanding of unsteady transonic flows. For example, configurations tested at the Langley Research Center include a clipped delta wing with a 6 percent thick circular arc airfoil section, ${ }^{8}$ an advanced transport wing with several oscfliating 
controls, ${ }^{y}$ an oscillating rectangular wing with a supercritical airfoil, 10 and a flexible supercritical wing from the DAST ARW-2 vehicle. 11

Pressures for the rectangular wing have been calculated using XTRAN3S. 12 Calculations have also been made for the $F-5^{13}, 1^{14}$ and LANN wings 15 which were tested at NLR, 15,16 and for the AGARD SMP tailplane model ${ }^{1 /}$ tested by the British RAE. ${ }^{18}$

These calculations give an indication of the capability of XTRAN3S to predict steady and unsteady pressures on rigid oscillating models. However, XTRAN3S also includes the capability of computing static aeroelastic deformation and transient time history responses for flutter analyses. The test of the second Aeroelastic Research Wing (ARW-2) in NASA's Drones for Aerodynamic and Structural Testing (DAST) prograin in the Langley Transonic Dynamics Tunnel 11 provides an opportunity to evaluate this capability. Comparisons of some of the data from this test with aeroelastic XTRAN3S calculations are given in this paper.

A brief description of the DAST ARW-2 wing and the wind tunnel test is first presented. Then overall descriptions of the XTRAN3S progran and a recently-developed grid coordinate transformation are given. Calculated and measured results are presented for static pressures and for wing-tip deflections. A brief trend study of static aeroelastic effects is described, and some efforts to calculate the experimental transonic instability boundary are discussed.

\section{Description of Wing and Test}

The right wing panel of the DAST ARW-2 flight vehicle was tested in the Langley Transonic Dynamics Tunnel (TDT) as shown in Figure 1. It was mounted on top of a half-body fuselage. The wing has a supercritical airfoil section, an aspect ratio of 10.3, and a leading-edge sweepback angle of $28.8^{\circ}$. The wing thickness is 15,12 , and 11 percent chord at $\bar{n}=0.071,0.426$, and 1.00 (the root, trailing edge break, and tip stations) respectively, with a linear variation of thickness between these span stations. The wing planform and overall arrangement are shown in Figure 2. The wing has two inboard control surfaces and an outboard control surface which are hydraulically controlled. For this test, the inboard surfaces were not used but were hydraulically held at zero deflection. The outboard surface was deflected both statically and dynamically in order to excite the model.

The design condition for the wing is $M=0.80, C_{L}=0.53$, and $q=125$ psf. The ARW-2 wing was designed to require active flutter control within its flight envelope.

The primary instrumentation consisted of 191 pressure transducers, 10 accelerometers, and wing root strain gages. The orifice rows of upper and lower surface pressure transducers were located at $\frac{n}{n}=0.274,0.476,0.599,0.707$, 0.871 , and 0.972 which correspond to the dimensional locations shown in Figure 2. Steady and unsteady pressures were measured for a large number of test conditions in the TDT using Freon as a test medium. The test conditions at which pressure data were obtained are shown in Figure 3. Data were obtained at Mach numbers of 0.6 , $0.7,0.8,0.85$, and 0.88 and at dynamic pressures of 100, 200, and 300 pounds per square foot (psf). At each tunnel condition static pressure data were obtained for wing root angles-of-attack of -2 to 4 degrees. Some of the higher angle-of-attack values were eliminated at the higher dynamic pressures due to wing loading limits. Unsteady pressure data were obtained at wing angles-of-attack of 0 and 2 degrees for control surface oscillation amplitudes of 1,2 , and 3 degrees and frequencies of 5,15 , and $20 \mathrm{~Hz}$.

An unsual wing instability was encountered in the wind tunnel test. This instability boundary is shown in Figure 4 and occurred at a nearly constant Mach number of about 0.90 for dynamic pressures from near 50 psf to above 300 psf. The frequency of this instability ranged from about $8.6 \mathrm{~Hz}$ at the low dynamic pressure to approximately $13 \mathrm{~Hz}$ at the higher dynamic pressure. The wing instability motion was dominated by the wing first bending mode which had a measured frequency of $8.3 \mathrm{~Hz}$ at wind-off conditions. The instability was found to be sensitive to angle of attack, with minimum damping occurring near zero degrees.

For aeroelastic analysis of the wing, the mode shapes of the wing are required. The mode shapes were obtained from a finite element model which was based on measured wing stiffness and agreed well with wind-off node lines and frequencies measured during the tunnel test. The first eight mode shapes used in the aeroelastic analys is and their corresponding frequencies are shown in Figure 5 . The first mode is first wing bending. The second mode is primarily fore and aft motion with some second wing bending motion. The third mode is primarily second wing bending. The natural frequencies of the second and third modes are very close to one another. The fourth and fifth modes, first torsion and third bending respectively, also exhibit frequencies relatively close to one another. The same is also true of the sixth and seventh modes, which are second wing torsion and a coupling of second wing torsion and third wing bending. Further details of the wing and test program are given in ref. 11 .

\section{XTRAN3S Program Description}

The modified unsteady transonic small perturbation (TSP) potential equation that is solved by XTRAN3S' is

$$
\begin{gathered}
M^{2}\left(\phi_{t}+2 \phi_{x}\right)_{t}=\left[\left(1-M^{2}\right) \phi_{x}+F \phi_{x}^{2}+G \phi_{y}^{2}\right]_{x} \\
+\left(\phi_{y}+H \phi_{x} \phi_{y}\right)_{y}+\left(\phi_{z}\right)_{z}
\end{gathered}
$$

where the spatial coordinates $x, y$, and $z$ are normalized by $c_{r}$, the reference chord, and $t$ is normalized by $c_{r} / V$. Here the time scale factor $\bar{k}$ of ref. 7 is 1.0 . The perturbation velocity potential $\phi$ is normalized by $c_{r} V$. 
The coefficients for the nonlinear terms in equation (1) can be defined as either ${ }^{1 y}$

$$
\begin{aligned}
& F=-\frac{1}{2}(\gamma+1) M^{2} . \\
& G=\frac{1}{2}(\gamma-3) M^{2} . \\
& H=-(\gamma-1) M^{2}
\end{aligned}
$$

$o r^{20}$

$$
\begin{aligned}
& F=-\frac{1}{2}\left[3-(2-\gamma) M^{2}\right] M^{2} \\
& G=-\frac{1}{2} M^{2} \\
& H=-M^{2}
\end{aligned}
$$

For $F=G=H=0$ the linearized unsteady potential equation is obtained. The coefficients given by equation (2) are used for the calculations of this report for the ARW-2 wing.

The boundary conditions imposed on the outer edges of the computational region are

$$
\begin{aligned}
\phi_{y} & =0 & & \text { upstream } \\
\phi_{x}+\phi_{t} & =0 & & \text { downstream } \\
\phi_{z} & =0 & & \text { above and below } \\
\phi_{y} & =0 & & \text { wing root } \\
\phi_{y} & =0 & & \text { far spanwise } \\
\left\lfloor\phi_{z}\right\rfloor=\left\lfloor\phi_{x}+\phi_{t}\right\rfloor & =0 & & \text { wake }
\end{aligned}
$$

where $\|$ indicates the jump in a quantity across the wake.

The wing flow tangency condition is

$\phi_{z}^{ \pm}=R_{x}^{ \pm}+R_{t}^{ \pm} ; z=0^{ \pm}, x_{L E} \leq x \leq x_{T E}$

where $R=r / c_{r}$.

The above conditions are those that are incorporated in the version of XTRAN3S code used for the computations reported in this paper (Version 1.5 with modified grid mapping). The outer boundary conditions recently have been improved by whitlow 21 by implementing characteristic or "nonreflecting" boundary conditions. Calculations have indicated that these characteristic boundary conditions significantly reduce the reflection of disturbances from the computational boundaries.

The XTRAN3S program has the capability for static and dynamic aeroelastic analyses of isolated wing configurations." The structural equations of motion are based upon a linear analysis using natural vibration modes for both static and dynamic deformations. Numerical integration of the structural equations is performed for each time step along with the aerodynamic calculations giving the generalized coordinate of each natural mode at each time step. The natural vibration mode shapes and their associated generalized mass and generalized stiffness matrices are required as input data.

\section{Coordinate Transformation}

The finite difference grid contains $60 \times 20 \times 40$ points in the $x, y$, and $z$ directions for a total of 48,000 points. In physical space the grid conforms to the wing planform and is mapped to a rectangular domain using the shearing transformation

$$
\xi=\xi(x, y), n=y, \zeta=z \text {, and } \tau=t
$$

In computational space equation (1) becomes

$$
\begin{aligned}
M^{2} \frac{\partial}{\partial \tau}[ & \left.\frac{1}{\xi_{x}} \phi_{\tau}+2 \phi_{\xi}\right]=\frac{\partial}{\partial \xi}\left[\left(1-M^{2}\right) \xi_{x} \phi_{\xi} .\right. \\
& +F \xi_{x}{ }^{2} \phi_{\xi}^{2}+G \xi_{y}{ }^{2} \phi_{\xi}{ }^{2}+2 G \xi_{y} \phi_{\xi} \phi_{n}+G_{\phi_{n}}{ }^{2} \\
& \left.+\frac{\xi_{y}}{\xi_{x}}\left(\xi_{y} \phi_{\xi}+\phi_{n}\right)+H \xi_{y} \phi_{\xi}\left(\xi_{y} \phi_{\xi}+\phi_{n}\right)\right] \\
& +\frac{\partial}{\partial \eta}\left[\frac{1}{\xi_{x}}\left(\xi_{y} \phi_{\xi}+\phi_{n}\right)+H \phi_{\xi}\left(\xi_{y} \phi_{\xi}+\phi_{n}\right)\right] \\
& +\frac{\partial}{\partial \zeta}\left[\frac{1}{\xi_{x}} \phi_{\zeta}\right]
\end{aligned}
$$

to transform the streanwise coordinate. From equation (5), $\xi_{x}=1 / c(y)$, and $\xi_{y}$ can be calculated analytically from equation (5). Using equation (5) results in a physical computational region whose streamwise extent is proportional to the local chord at each span station. For highly swept and tapered wings, the mesh is highly skewed in the far field of the physical domain. The resulting skewness of the grid led to numerical instabilities that restricted the application of XTRAN3S to wings of low sweep and low taper. The grid has been revised such that in the physical domain, the computational region is a rectangular box thus alleviating the skewness of the grid.

Versions of this type of grid arrangement have been given previously. 13,14 In ref. 13 a smooth stretching was used to map the regions from the wing to the upstream or downstream boundaries. Good results were obtained for the F-5 wing which is highly swept and highly tapered. In ref. 14, equation (5) is used on the wing and similar equations are used in the upstream and downstream regions with $c(y)$ replaced by the local distance from the wing to the boundary of the region. This latter technique permits analytical evaluation of $\xi_{x}$ and $\xi_{y}$, but results in discontinuous values of these quantities at the leading and trailing edges. Even with these discontinuous values, results comparable to those of ref. 13 have been obtained for the F-5 wing. ${ }^{14}$

Herein, a finite difference grid is used that is similar to that of ref. 13. In the physical domain the grid is described analytically to give a smoothly-varying mesh spacing. The values of $\xi_{x}$ and $\xi_{y}$ are then calculated numerically using second order finite difference formulae at each point in the computational domain. The $\xi$-distribution of 
points (for all values of $n$ ) in the $\xi-n$ domain is chosen to be the same as the $x$-distribution of points along the root chord in the physical domain.

\section{Finite Difference Grid}

The $x-y$ grid used for the computations presented in this report is shown in Figure 6 along with the wing planform. The grid is defined in the following manner. First, equation (5) is used on the wing planform. The $x$-spacing of points along the chord essentially is that developed in references 12 and 22 , with 39 points along the local chord; 38 points are equispaced from $x / c=1 / 38$ to 1.0 , and an additional point is located at

$x / c=1 /(3 \times 38)$. The grid extends from 20 wing root chords upstream of the wing root leading edge to 20 chords downstream of the wing root trailing edge. Eleven grid lines are used ahead of the wing and ten aft. The wing leading edge is centered between grid lines. The spacing ahead of the wing is given by

$$
\begin{aligned}
x_{i_{u}} & =x_{L E}+A_{1} i_{u}+A_{3} i_{u}^{3}, i_{u}=1, \ldots i_{U P} \\
A_{3} & =\frac{x_{U P}-x_{L E}}{i_{U P}\left(i_{U P}^{2}-1\right)}-\frac{x_{1}-x_{L E}}{i_{U P}^{2}-1} \\
A_{1} & =x_{1}-x_{L E}-A_{3}
\end{aligned}
$$

where

$$
\begin{aligned}
& x_{1}=x_{1}(y)=\begin{array}{l}
x \text {-coordinate of first point } \\
\text { on wing }
\end{array} \\
& x_{L E}=x_{L E}(y)=x \text {-coordinate of leading edge } \\
& x_{U P}=\begin{array}{c}
x \text {-coordinate of upstream boundary } \\
\text { (constant) }
\end{array}
\end{aligned}
$$

and $i_{u}$ is the index of the points starting at the leading edge and running to the upstream boundary. Similarly downstream,

$$
\begin{aligned}
& x_{i_{d}}=x_{T E}+B_{1} i_{d}+B_{3} i_{d}^{3}, i_{d}=1, \ldots i_{D N} \\
& B_{3}=\frac{x_{D N}-x_{T E}}{i_{D N}\left(i_{D N}^{2}-1\right)}-\frac{x_{W}-x_{T E}}{i_{D N}^{2}-1} \\
& B_{1}=x_{W}-x_{T E}-B_{3}
\end{aligned}
$$

where

$$
\begin{aligned}
& x_{W}=x_{W}(y)=\begin{array}{l}
x \text {-coordinate of first } \\
\text { point downstream of wing }
\end{array} \\
& x_{T E}=x_{T E}(y)=\begin{array}{l}
x \text {-coordinate of trailing } \\
\text { edge }
\end{array} \\
& x_{D N}=\begin{array}{l}
\text { x-coordinate of downstream boundary } \\
\text { (constant) }
\end{array}
\end{aligned}
$$

and $i_{d}$ is the index of the points starting aft of the trailing edge and running to the downst ream boundary.
Fourteen rows of points are used along the span of the wing (including the points inboard of and on the plane of symmetry). The rows are distributed along the span using a cosine distribution

$n_{j}=n_{T I P} \cos \left[\frac{\pi}{2}\left(\frac{j_{w}-j+1}{j_{w}-1}\right)\right], j=1, \ldots, j_{w}$

where $n_{T_{p}}=$ semispan $/ c_{r}$ and $j_{w}=$ number of grid'tows on the wing (14 here). The first spanwise station is at $12 \%$ span and the last one at $99.3 \%$ span. This distribution of grid points is used to emphasize the definition of lpads in the tip region which are critical for aeroelastic analyses.

Outboard of the tip, the wing planform is extended smoothly to the far spanwise boundary at 1.5 semispan. The midchord line of the wing is extended to the far spanwise boundary as a parabola that has the slope of the wing midchord at the tip and is perpendicular to the outer grid boundary. The wing leading and trafling edges are extended using cubic equations that match leading and trailing edge slopes and intersect the outer grid boundary perpendicularly at one half the tip chord fore and aft of the midchord extension. The equations defining these grid points are

$x_{L E}(n)=x_{L E}{ }_{T I P}+D_{1}\left(n-n_{T I P}\right)+D_{2}\left(n-n_{T I P}\right)^{2}$

where

$$
+D_{3}\left(n-n_{T I P}\right)^{3}
$$

and

$$
\begin{aligned}
& D_{1}=\left.\frac{d x_{L E}}{d \eta}\right|_{T I P} \\
& D_{2}=\frac{1}{\Delta n_{0}^{2}}\left[-2 D_{1} \Delta n_{0}+3\left(x_{L E_{O B}}-x_{L E}{ }_{T I P}\right)\right] \\
& D_{3}=\frac{1}{\Delta n_{0}^{3}}\left[D_{1} \Delta n_{0}-2\left(x_{L E_{O B}}-x_{L E_{T I P}}\right)\right]
\end{aligned}
$$

$$
\begin{aligned}
{ }^{\Delta n_{O}}= & n_{O B}-n_{T I P} \\
{ }_{T I P}= & n \text {-coordinate of wing-tip } \\
{ }^{n_{O B}}= & n \text {-coordinate of far spanwise } \\
& \text { extent of grid } \\
x_{L E_{T I P}} & \begin{array}{l}
\text { edge } \\
\text { edgeordinate of wing-tip leading }
\end{array} \\
x_{L E_{O B}}= & \begin{array}{l}
\text { x-coordinate of leading edge of } \\
\text { outboard extension of wing }
\end{array}
\end{aligned}
$$

Similarly for the tratling edge extenston

$$
\begin{aligned}
x_{T E}(n)=x_{T E_{T I P}} & +E_{1}\left(n-n_{T I P}\right)+E_{2}\left(n-n_{T I P}\right)^{2} \\
& +E_{3}\left(n-n_{T I P}\right)^{3}
\end{aligned}
$$


where

$$
\begin{aligned}
& E_{1}=\left.\frac{d x_{T E}}{d n}\right|_{T I P} \\
& E_{2}=\frac{1}{\Delta n_{0}^{2}}\left[-2 E_{1} \Delta \eta_{0}+3\left(x_{T E_{O B}}-x_{T E_{T I P}}\right)\right] \\
& E_{3}=\frac{1}{\Delta n_{0}^{3}}\left[E_{1} \Delta \eta_{0}-2\left(x_{T E_{O B}}-x_{T E_{T I P}}\right)\right]
\end{aligned}
$$

and

$$
\begin{aligned}
{ }^{x_{T E}}= & x \text {-coordinate of wing trailing } \\
& \text { edge at tip } \\
{ }^{x_{T E}}= & \begin{array}{l}
x \text {-coordinate of trailing edge of } \\
\text { outboard extension of wing }
\end{array}
\end{aligned}
$$

The outboard extension of the midchord line intercepts the right hand boundary at

$$
x_{M_{O B}}=x_{M_{T I P}}+\left(\left.\frac{d x_{M}}{d n}\right|_{T I P}\right) \Delta n_{0}
$$

where $\left.\frac{d x_{M}}{d \eta}\right|_{\text {TIP }}=\left(D_{1}+E_{1}\right) / 2$

and offsetting by $\pm \mathrm{c}_{\mathrm{TIP}} / 2$,

$$
\begin{aligned}
& x_{L E_{O B}}=x_{M_{O B}}-c_{T I P} / 2 \\
& x_{T E_{O B}}=x_{M_{O B}}+c_{T I P} / 2
\end{aligned}
$$

The same streamwise distribution of points that is used on the wing is used between these outboard extension of the leading and trailing edge grid lines.

The $n$-distribution of points outboard of the wing-tip is given by a cubic equation. The first row of points outboard of the wing and the last row on the wing are located symetrically about the tip. Also applying a zero second derivative condition at the tip gives

$$
\begin{aligned}
n_{j 0} & =c_{1} j_{0}+c_{3} j_{O}^{3}+n_{T I P}, j_{O}=1, \ldots j_{O B} \\
c_{1} & =\frac{j_{O B}\left(n_{O I}-n_{T I P}\right)-\left(n_{O B}-n_{T I P}\right)}{j_{O B}\left(j_{O B}^{2}-1\right)} \\
c_{3} & =\frac{\left(n_{O B}-n_{T I P}\right)-j_{O B}\left(n_{O 1}-n_{T I P}\right)}{j_{O B}\left(j_{O B}^{2}-1\right)}
\end{aligned}
$$

$\mathrm{J}_{\mathrm{OB}}=$ number of spanwise points outboard of wing-tip

$j_{0}=$ index of points outboard of wing-tip $n_{01}=\begin{aligned} & n-1 \text { ocation of first point outboard of } \\ & \text { wing-tip }\end{aligned}$

In the z-direction, the grid extends 25 root chords above and below the wing. Twenty planes of points are used above and 20 planes are used symmetrically below the wing. The distribution of points is that developed and applied in references 12 and 22 .

The resulting grid is smooth and embeds the planform smoothly. This grid appears to be reasonable, but since to date only limited variations have been investigated for three dimensional configurations, the grid cannot be considered an optimal choice. The grid is reasonably fine on the wing but is relatively coarse off the wing.

\section{Results and Discussion}

Calculations have been made with XTRAN3S for the DAST ARW-2 wing for a range of Mach numbers from 0.60 to 0.90 , for zero wing root angle of attack, and for the aileron undeflected. Static aeroelastic calculations for the flexilbe wing have been made for dynamic pressures up to 1000 psf. Static pressure calculations were made for the rigid wing for a limited range of Mach numbers. Limited dynamic aeroelastic calculations were made to explore the wing instability near $M=0.90$.

The measured airfoil ordinates have been used to determine the wing surface slopes required for input to XTRAN3S. The measured ordinates were fitted with a parametric spline with smoothing, ${ }^{23}$ and the slopes were calculated from the spline fit. The mode shapes from the finite element model were interpolated to the XTRAN3S computational grid locations with a surface spline. ${ }^{24}$

Steady Pressure Distributions.- For the rigid wing, calculated static pressures for several Mach numbers are shown in Figure 7. The upper and lower surface pressures are shown for zero angle of attack. The upper surface pressures are supercritical at $M=0.75$ in the outboard region of the wing, and at $M=0.80$ a strong shock wave is calculated which is very pronounced in the outboard region of the wing. Attempts to obtain the static rigid solution at $M=0.81$ were unsuccessful.

The variation of calculated static pressures with dynamic pressure at $M=0.8$ for the flexible wing is shown in Figure 8 . The dynamic pressure is varied from zero (rigid wing) to $900 \mathrm{psf}$. The addition of wing flexibility alleviates the strong shock wave on the upper surface in the outboard region of the wing. This is a result of the wing-tip washout which occurs with increasing dynamic pressure where in the wing is twisted nosedown and deflected upwards. 
Calculated static pressures for the flexible wing for several Mach numbers and a dynamic pressure of 300 psf are shown in Figure 9. With the addition of the static aeroelastic deformation, calculations with XTRAN3S were made up to $M=0.90$. The upper surface pressures are supercritical at $M=0.80$ with the shock being the strongest in the center span region. With increasing Mach number the upper surface shock becomes stronger and moves to the trafling edge. In addition, a shock begins to form on the lower surface in the wing-tip region at $M=0.85$ and becomes stronger and moves inboard at $M=0.90$. The strong shocks located aft on the wing for $M=0.85$ and 0.90 are not considered realistic and these cases are considerably beyond the design Mach number of 0.80. The pressure distributions at these conditions are similar to those seen in two-dimensional potential flow calculations when the assumption of isentropic flow is violated. 5

Comparisons of calculated static pressures for the flexible wing with wind tunnel data are shown in Figure 10 for $M=0.70,0.80$, and 0.85. Figure $10(a)$ shows upper and lower surface static pressure distributions for $M=0.70$, a dynamic pressure of 200 psf and zero angle of attack. The agreement of the calculated pressures with experiment is only fair. The lower surface pressure in the inboard region is underpredicted along the chord and there is a consistent underprediction in the leading edge region along the span. The agreement between theory and experiment is better in the outer span region. Although not shown here, similar agreement between measured and calculated pressures was observed for $q=100$ and 300 psf at $M=0.70$ and for $q=100$, 200 , and 300 psf at $M=0.60$. The flow is subcritical at these conditions.

Similar agreement is not seen for cases with supercritical flow. Figures $10 \mathrm{~b}, 10 \mathrm{c}$, and lod show comparisons of measured and calculated pressures at $M=0.8$ for $q=100,200$ and 300 psf, respectively. No shocks are seen in the measured data for these cases. In contrast, the calculations show moderate to strong shocks except for the outboard station at $q=200$ (Fig. 10c) and 300 psf (Fig. 10d). Also, the calculations overpredict the upper surface pressures and underpredict the lower surface pressures on the forward portion of the wing. Increasing dynamic pressure increases wing-tip washout and the agreement with experiment improves in the wing-tip region. For $q=200$ psf, (Figure $10(\mathrm{c})$ ), the shock calculated at the outboard station is in good agreement with experiment. As the dynamic pressure increases to $300 \mathrm{psf}$, (Figure 10 (d)), the shock vanishes outboard. Finally, Figure 10(e) shows the static pressure distributions at $M=0.85$ for $q=200$ psf. Similar to $M=0.8$, the upper surface shock strength is overpredicted over the entire wing and the lower surface pressure is underpredicted inboard and along the wing leading edge.

The calculations using XTRAN3S have shown reasonable trends but only fair agreement with the measured data for cases of subcritical flow. Larger discrepancies are indicated for cases with strong calculated shock waves. The calculations do not include either the effects of the fuselage or a viscous boundary layer, each of which may have a large effect in transonic flow. Further effort is needed to improve the agreement with the experimental data possibly by including the fuselage and boundary layer, or by improving the analys is in other respects such as the number of grid points and so forth.

Static Aeroelastic Effects.- The static aeroelastic deformation at the wing-tip is shown in Figure 11. The experimental and calculated wing-tip vertical displacement, $z_{t}$, and rotation, $\theta_{t}$, are shown for varying dynamic pressure at $M=0.8$ and zero wing root angle of attack. The calculations were made for increments of 100 psf in q. Both the computational and experimental wing-tip deflections, $z_{t}$, are nonlinear with dynamic pressure which would not be expected from linearized aerodynamic theories. The wing-tip displacement is approximately $40 \%$ overpredicted at $q=300$ psf, which is expected from the overpredicted upper surface pressures shown in Figure $10(d)$. The calculated tip displacement reaches a maximum of approximately 10 inches at $\mathrm{q}=600$ psf. The calculated wing tip twist angle, $\theta_{t}$, is in good agreement with the experimental data although this agreement may be fortuitous. One test point taken in air is included in Figure 11 and agrees with the measurements in Freon within the range of experimental scatter.

A comparison of calculated wing-tip deflections at two Mach numbers versus dynamic pressure is shown in Figure 12. The predicted deflection data at $M=0.70$ are very similar to that for $M=0.80$. At the lower Mach number the wing-tip deflections are also nonlinear with dynamic pressure even though the flow is subcritical for $M=0.70$. Although the $t$ ip deflections are slightly less at $M=0.70$, they are of the same order of magnitude as at $M=0.80$.

The variation of calculated wing-tip deflections with Mach number at $q=300$ psf is shown in Figure 13. The calculations were made for increments of 0.05 in Mach number up $M=0.80$ and for increments of 0.01 between $M=0.80$ and $M=0.90$. The wing-tip vertical displacement and rotation vary silightly with Mach number between $M=0.60$ to 0.80 . However, above $M=0.80$ the wing-tip nose-down twist increases rapidly with increasing Mach number and the wing displacement rises sharply to a maximum. These effects are caused by the development of strong shocks moving aft along the wing as seen for $M=0.85$ and 0.90 in Figure 9. The sharply increasing nose down twist of the wing-tip with increasing Mach number above $M=0.80$ is qualitatively similar to that observed on the model during the test. Similarly, the wing-tip displacement shown in Figure 13 is similar to that observed in the test even though the detailed calculated pressures do not compare well with experiment. The rapid increase in wing-tip displacement and rotation beyond $M=0.80$ is expected for Mach numbers above the design cruise condition. 
The variation of predicted wing lift and pitching moment with Mach number for the flexible $\langle q=300)$ and rigid wing $(q=0)$ is shown in Figure 14. The results for both the rigid and flexible wing show a nonlinear increase in the magnitude of the 1 ift and the mornent coefficients with Mach number. As previously noted, attempts to calculate the rigid wing above $M=0.80$ were unsuccessful. Above $M=0.80$ the forces on the flexible wing rapidly increase unt il $M=0.88$ where the loads reach a maximum and begin to decrease.

The variation of predicted wing lift and pitching moment with dynamic pressure for $M=0.70$ and $M=0.80$ is shown in Figure 15 . As in the comparison of wing-tip deflections at these Mach numbers, the data for $M=0.70$ is very similar to that for $M=0.80$. For both Mach numbers the effect of wing flexibility is quite significant.

The trends shown here for the effects of flexibility are large, significant, and are of considerable interest. It must be kept in mind that these results will be affected by the lack of agreement of the calculated and measured static pressures. Further effort is needed to calculate these efforts accurately with codes such as XTRAN3S on thick supercritical wings.

Aeroelastic Stability Calculations.- Dynamic aeroelastic calculations were made with XTRAN3S in an attempt to predict the instability boundary encountered during the wind tunnel test and shown in Figure 4 . The aeroelastic transient calculations were made for $q=300$ psf at Mach numbers up to 0.90 . No instability was encountered. It should be noted that, as previously shown, the agreement of calculated pressure distributions with experiment degrade rapidly for Mach numbers greater than 0.70 . If the angle of attack were adjusted to match pressures at the higher Mach numbers, it is possible that the instability boundary might be calculated.

\section{Concluding Remarks}

An overview of the transonic small perturbation program XTRAN3S and a recently-developed grid coordinate transformation has been given. Results calculated using XTRAN3S have been compared with data measured for the DAST ARW-2 wing in the Langley Transonic Dynamics Tunnel. Several static aerodynamic cases were calculated for a rigid wing and with flexibility included. The addition of wing flexibility was shown to strongly influence the predicted static pressure for this wing. Predicted static pressures for the flexible wing were compared to wind tunnel data for Mach numbers from 0.70 to 0.85 for dynamic pressures from 100 to 300 psf and for zero wing root angle of attack. The calculated pressures were in fair agreement with experimental data for subcritical flow cases. For cases where the flow was supercritical the program overpredicted transonic effects such as the shock wave strength. The pressure along the leading edge was poorly predicted. The best agreement of pressures occurred near the wing-tip.
Trends of predicted wing-tip deflection and wing forces for a flexible wing were studied. At $M=0.80$ the predicted wing-tip displacement was approximately $40 \%$ high, but the tip rotation was close to the experimental value. The program predicted trends for wing-tip deflection which were qualitatively similar to those observed during the wind tunnel test, but were quantitatively overpredicted. The wing-tip deflections and forces were shown to be nonlinear with dynamic pressure and Mach number. The predicted displacements and forces rapidly increased in magnitude beyond the design Mach number of 0.80 and peaked at approximately $M=0.88$.

The XTRAN3S program was also used to investigate the dynamic stability of the wing. An attempt was made to calculate the instability observed during the tunnel test at $M \approx 0.90$. This attempt was unsuccessful and further effort is needed to improve the accuracy of the static flow field predictions which may in turn improve the calculation of this instability.

\section{Acknowledgment}

The authors wish to thank Mr. Robert w. Neely of Kentron International for assistance with modal and airfoil processing and Mr. Victor L. Spain of Kentron International for furnishing the vibration modes from the finite element model. The assistance of Dr. Woodrow Whitlow and $\mathrm{Mr}$. Robert $\mathrm{N}$. Desmarais in the development of the mapping transformation and grid is also gratefully acknowledged.

\section{References}

'Edwards, J. W., Bland, S. R., and Seidel, D. A., "Experience with Transonic Unsteady Aerodynamics Calculations," paper 5 in "Transonic Unsteady Aerodynamics and its Aeroelastic Applications," AGARD CP No. 374, January 1985.

${ }^{2}$ Goorjian, P. M., and Guruswamy, G. P., "Unsteady Transonic Aerodynamic and Aeroelastic Calculations About Airfoils and Wings," paper 14 in "Transonic Unsteady Aerodynamics and its Aeroelastic Applications," AGARD CP No. 374, January 1985.

${ }^{3}$ Guruswamy, P., and Goorjian, P. M., "Effects of Viscosity on Transonic-Aerodynamic and Aeroelastic Characteristics of 0scillating Airfoils," Journal of Aircraft, Vol. 21, No.9, September 1984, pp. 700-707.

"Howlett, J. T., "Effective Self-Consistent Viscous-Inviscid Solutions for Unsteady Transonic Flow," AIAA Paper No. 85-0482, presented at the AIAA 23rd Aerospace Sciences Meeting and Technical Display, Reno, Nevada, January 14-17, 1985.

'Fuglsang, D. F., and Williams, M. H., "Non-Isentropic Unsteady Transonic Small Disturbance Theory," AIAA Paper 85-0600, presented at AIAA/ASME/ASCE/AHS 26th Structures, Structural Dynamics and Materials Conference, Orlando, Florida, April 15-17, 1985. 
batina, J. T., "Unsteady Transonic Flow Calculations for Two-Dimensional Canard-Wing Configurations with Aeroelastic Applications," AIAA Paper 85-0585, presented at the AIAA/ASME/ASCE/AHS 26th Structures; Structural Dynamics and Materials Conference, Orlando, Florida, April 15-17, 1985.

'Borland, C. J., and Rizzetta, D. P., "Transonic Unsteady Aerodynamics for Aeroelastic Applications - Vol. I: Technical Development Summary," AFWAL TR 80-3107, Vol. I, June 1982.

yess, R. W., Wynne, E. C., and Cazier, F. W., Jr., "Static and Unsteady Pressure Measurements on a 50 Degree Clipped Delta Wing at $M=0.9, "$ NASA TM 83297, April 1982.

${ }^{y}$ Sandford, M. C., Ricketts, R. H., Cazier, F. W., Jr., and Cunningham, H. J., "Transontc Unsteady Airloads on an Energy Efficient Transport Wing with Oscillating Control Surfaces," Journal of Aircraft, Vol. 18, No. 7 , July 1981, pp. 557-561.

1 Uicketts, R. H., Sandford, M. C., Seidel, D. A., and Watson, J. J., "Transonic Pressure Distributions on a Rectangular Supercritical Wing Oscillating in Pitch," Journal of Aircraft, Vol. 21, No. 8, August 1984, pp. 576-582.

${ }^{11}$ Seidel, D. A., Sandford, M. C., and Eckstrom, C. V., "Measured Unsteady Transonic Aerodynamic Characteristics of an Elastic Supercritical Wing with an Oscillating Control Surface," AIAA Paper 85-0598-CP presented at the AIAA/ASME/ASCE/AHS 26th Structures, Structural Dynamics and Materials Conference, Orlando, Florida, April 15-17, 1985.

${ }^{12}$ Seidel, D. A., Bennett, R. M., and Ricketts, R. H., "Some Recent Applications of XTRAN3S," AIAA Paper 83-1811 presented at the AIAA Applied Aerodynamics Conference, Danvers, Massachusetts, JuTy 13-15, 1983.

13 Guruswamy, P. G., Goorjian, P. M., "An Efficient Algorithm for Unsteady Transonic Aerodynamics of Low Aspect Ratio Wings," Journal of Aircraft, Vol. 22, No. 3, March 1985, pp. 193-199.

${ }^{14}$ Borland, C. J., Sotomayer, W. A., "An Algorithm for Unsteady Transonic Flow About Tapered Wings," AIAA Paper 84-1567, AIAA 17th Fluid Dynamics, Plasma Dynamics, and Lasers Conference, Snowmass, Colorado, June 25-27, 1984.

1'Tijdeman, H., Van Nunen, J. W. G., Kraan, A. N., Persoon, A. J., Poestkoke, R., Roos, R., Schippers, P., and Siebert, C. M.., "Transonic Wind Tunnel Tests on an Oscillating Wing with External Store," AFFDL-TR-78-194, Parts I \& II December 1978.

${ }^{16}$ Ruo, S. Y., Malone, J. B., Horsten, J. J., and Houwink, R., "The LANN Program: An Experimental and Theoretical Study of Steady and Unsteady Transonic Airloads on a Supercritical Wing," AIAA Paper 83-1686 presented at the AIAA 16th Fluid and Plasma Dynamics Conference, Danvers, Massachusetts, July 12-14, 1983.
L'Bennett, R. M., Wynne, E. C., and Mabey, D. G. "Calculation of Transonic Steady and Oscillatory Pressures on a Low Aspect Ratio Model and Comparison with Experiment," presented at the 2nd International Symposium on Aeroelasticity and Structural Dynamics, Technical University of Aachen, Germany, April $1-3,1985$.

${ }^{18}$ Mabey, D. G., Welsh, B. L., and Cripps, B. E., "Measurements of Steady and Oscillatory Pressures on a Low Aspect Ratio Model at Subsonic and Supersonic Speeds," British RAE Technical Report 84095, September 1984.

${ }^{19}$ Lomax, H., Bailey, F. R., and Ballhaus, W. F., "On the Numerical Simulation of Three-Dimensional Transonic Flow with Application to the C-141 Wing," NASA TN D-6933, August 1973.

2UVan der Vooren, J., Sloof, J. W., Huizing, G. H., and van Essen, A., "Remarks on the Suitability of Various Transonic Small Perturbation Equations to Describe Three-Dimensional Transonic Flow, Examples of Computations Using a Fully-Converative Rotated Difference Scheme," Symposium Transsonicum II, Gottingen, West Germany, September 1975, proceedings, Springer-Verlag, Berlin, 1976. pp. $557-566$.

$21^{\text {Whitlow, W., Jr., "Characteristic }}$ Boundary Conditions for Three-Dimensional Transonic Unsteady Aerodynamics," NASA TM 86292, october 1984.

${ }^{22}$ Seide1, D. A., Bennett, R. M., and Whitlow, W., Jr., "An Exploratory Study of Finite-Difference Grids for Transonic Unsteady Aerodynamics," AIAA Paper No. 83-0503, presented at the AIAA 21st Aerospace Sctences Meeting and Technical Display, Reno, Nevada, January 10-13, 1983, also NASA TM 84583, December 1982.

"Desmarais, R. N., and Bennett, R. M., "Computer Programs for Plotting Curves with Vartous Dashed-1ine Sequences," NASA TM 2465, February 1972.

${ }^{24}$ Harder, R. L., and Desmarais, R. N., "Interpolation Using Surface Splines," Journal of Aircraft, Vol. 9, No. 2, February 1972, pp. 189-191.

2'Desmarais, R. N., and Bennett, R. M., "User's Guide for a Modular Flutter Analysis Software System (FAST Version 1.0)," NASA TM 78720 , May 1978. 


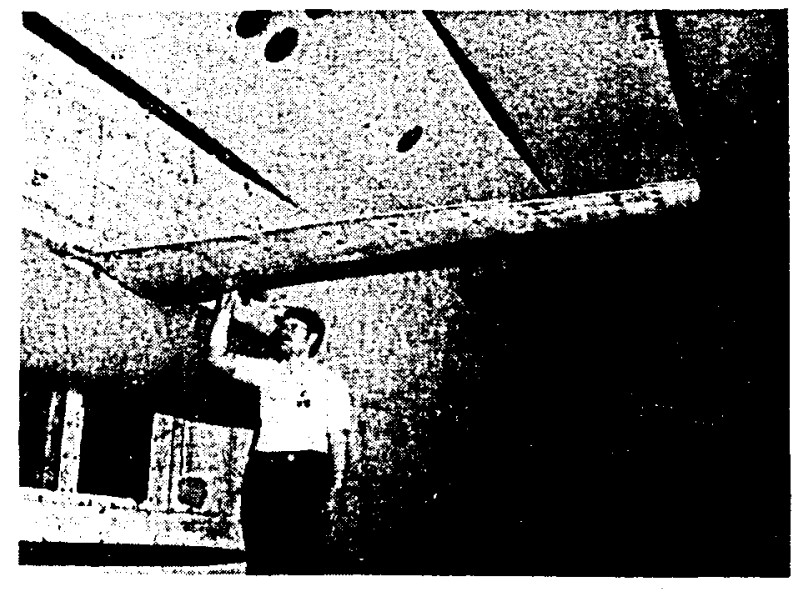

Fig. 1 Wing mounted in TOT test section.

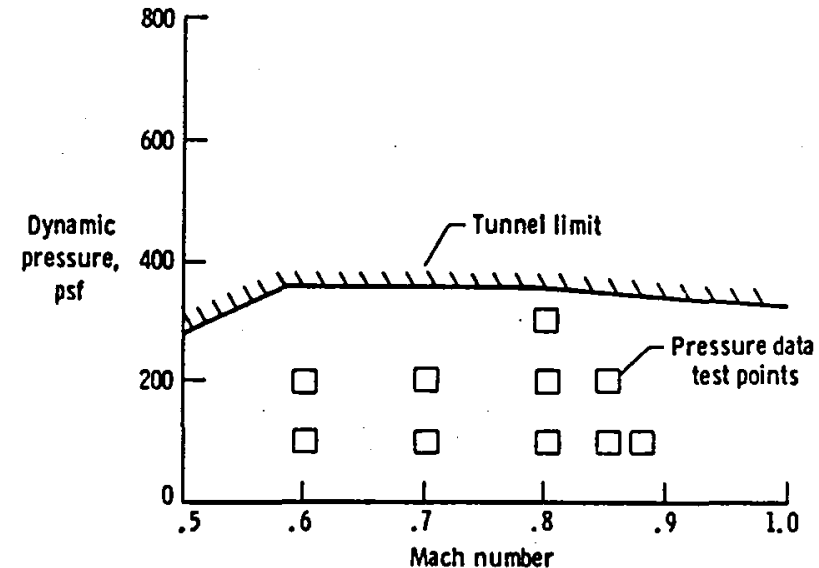

Fig. 3 Wind tunnel test conditions.

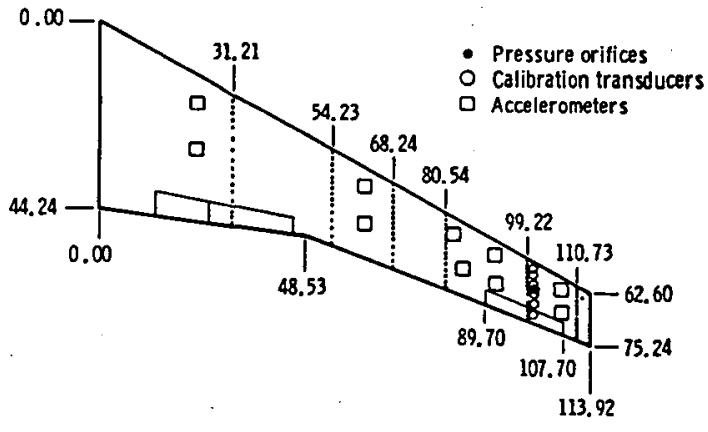

Fig. 2 Wing planform and instrumentation locations (in inches).

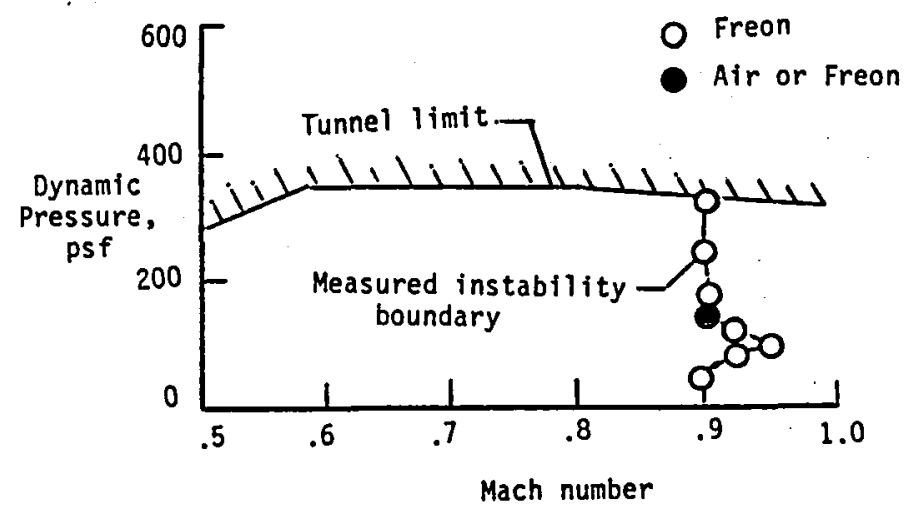

Fig. 4 Measured wing instability boundary. 


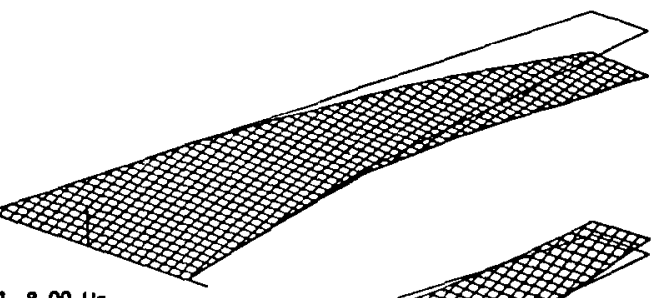

(a) Mode $1,8.09 \mathrm{~Hz}$
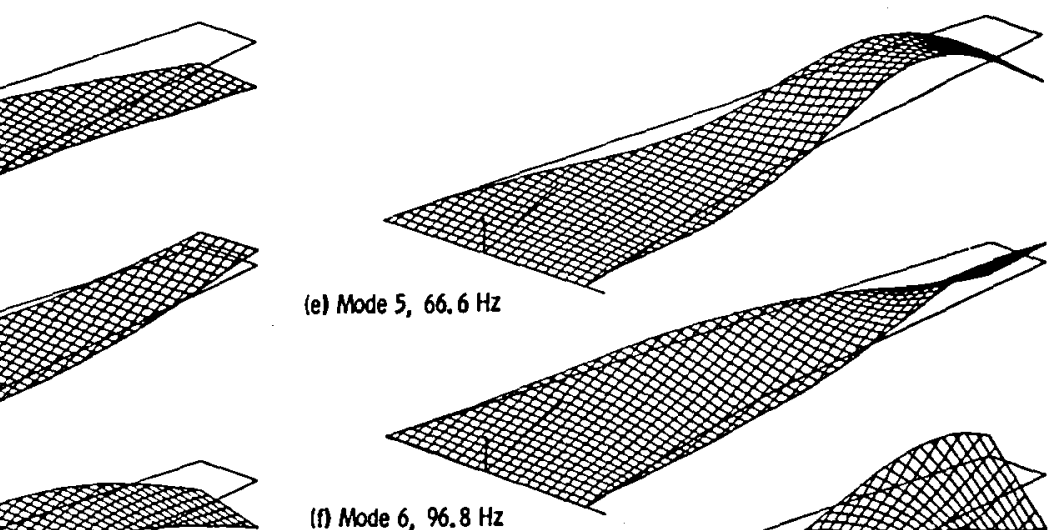

(b) Mode 2, $29.2 \mathrm{~Hz}$

(f) Mode $6,96.8 \mathrm{~Hz}$

(e) Mode $5,66.6 \mathrm{~Hz}$

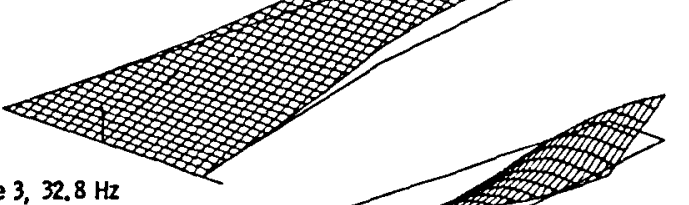

(c) Mode $3,32.8 \mathrm{~Hz}$

(g) Mode $7,104.7 \mathrm{~Hz}$

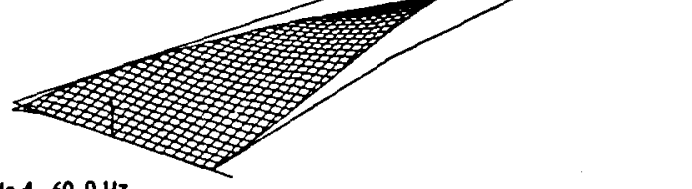

(d) Mode $4,60.9 \mathrm{~Hz}$

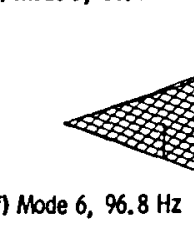

(h) Mode $8,117.2 \mathrm{~Hz}$

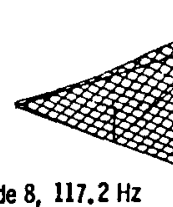

Fig. 5 Wing mode shapes and frequencies.

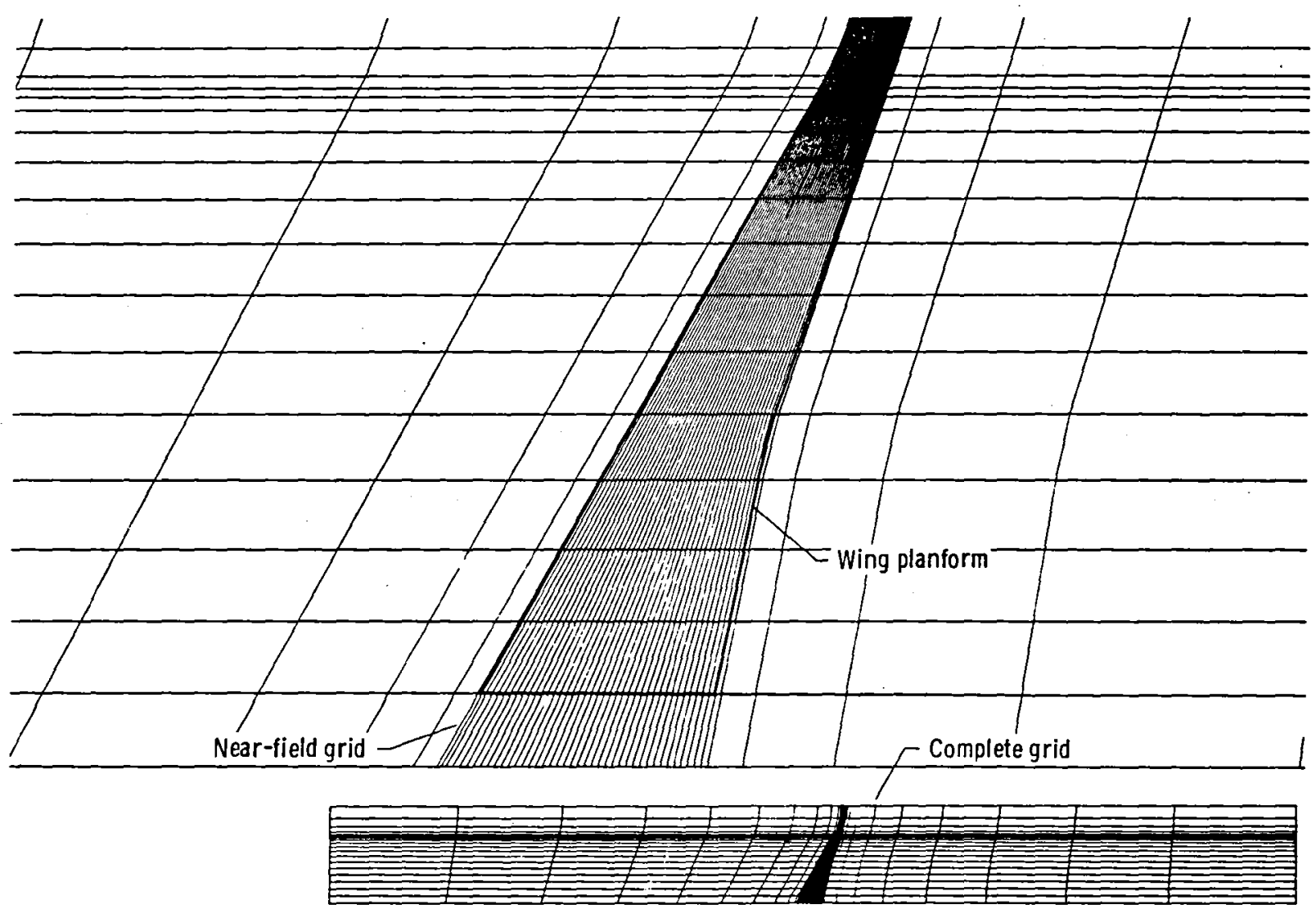

Fig. 6 Finite difference grid in the plane of the wing. 

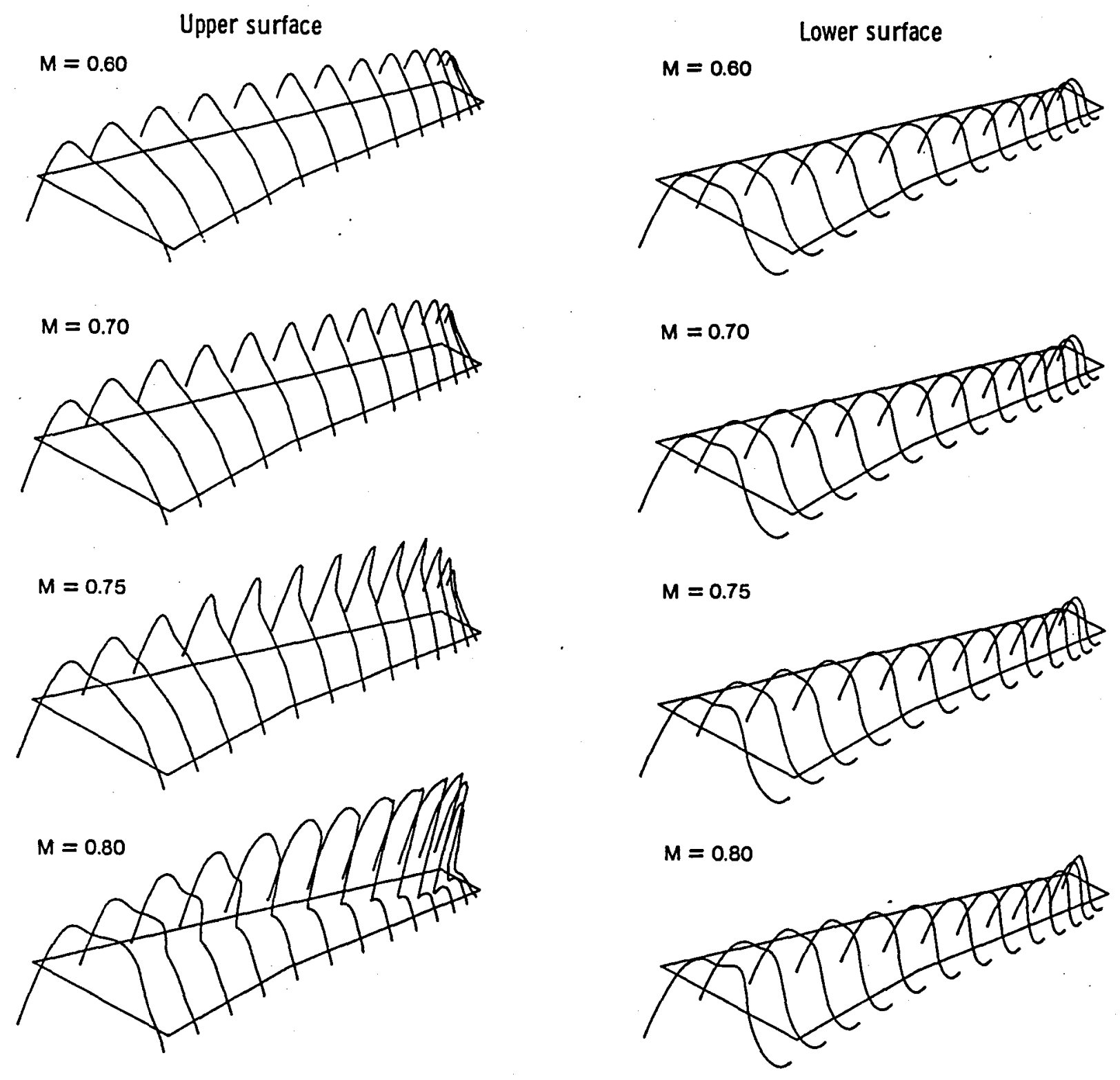

Fig. 7 Static pressure distributions for rigid wing versus Mach number, $\alpha=0^{\circ}$. 
Upper surface
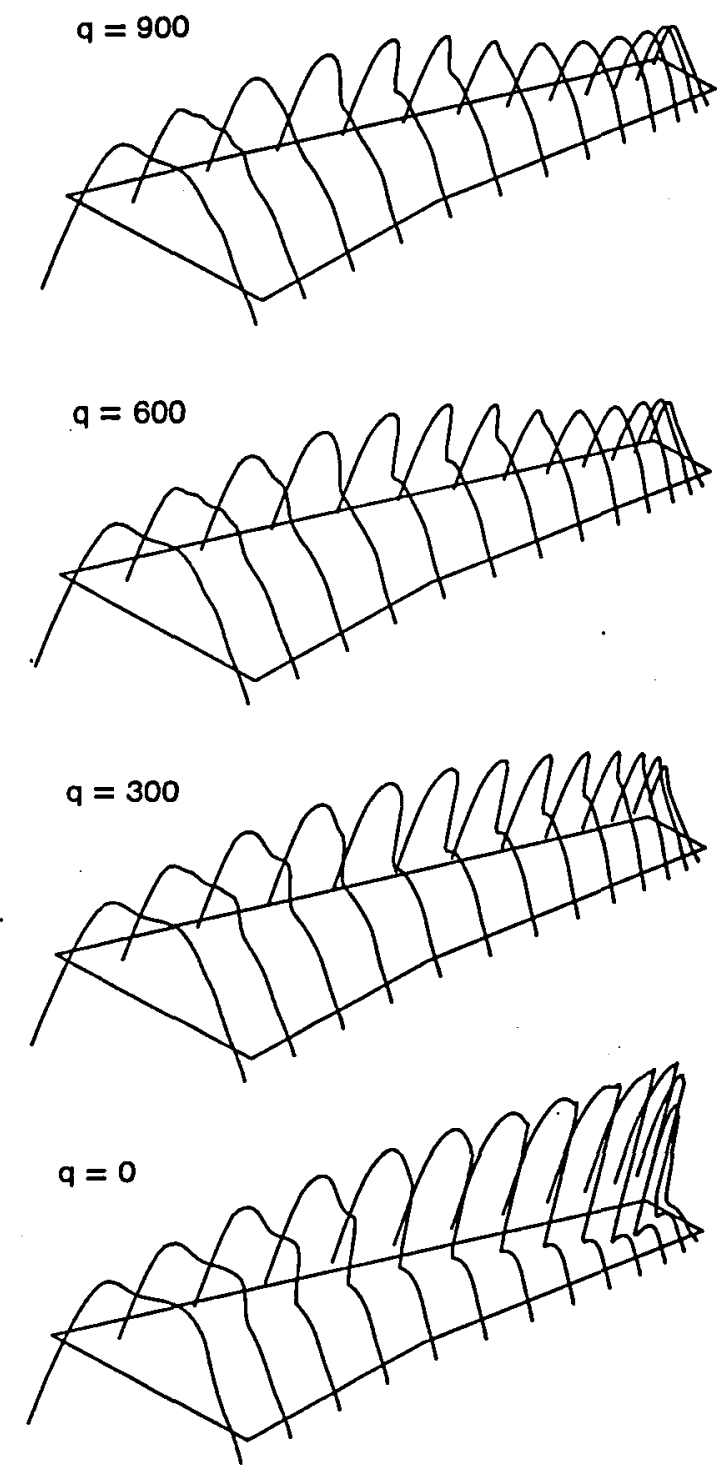
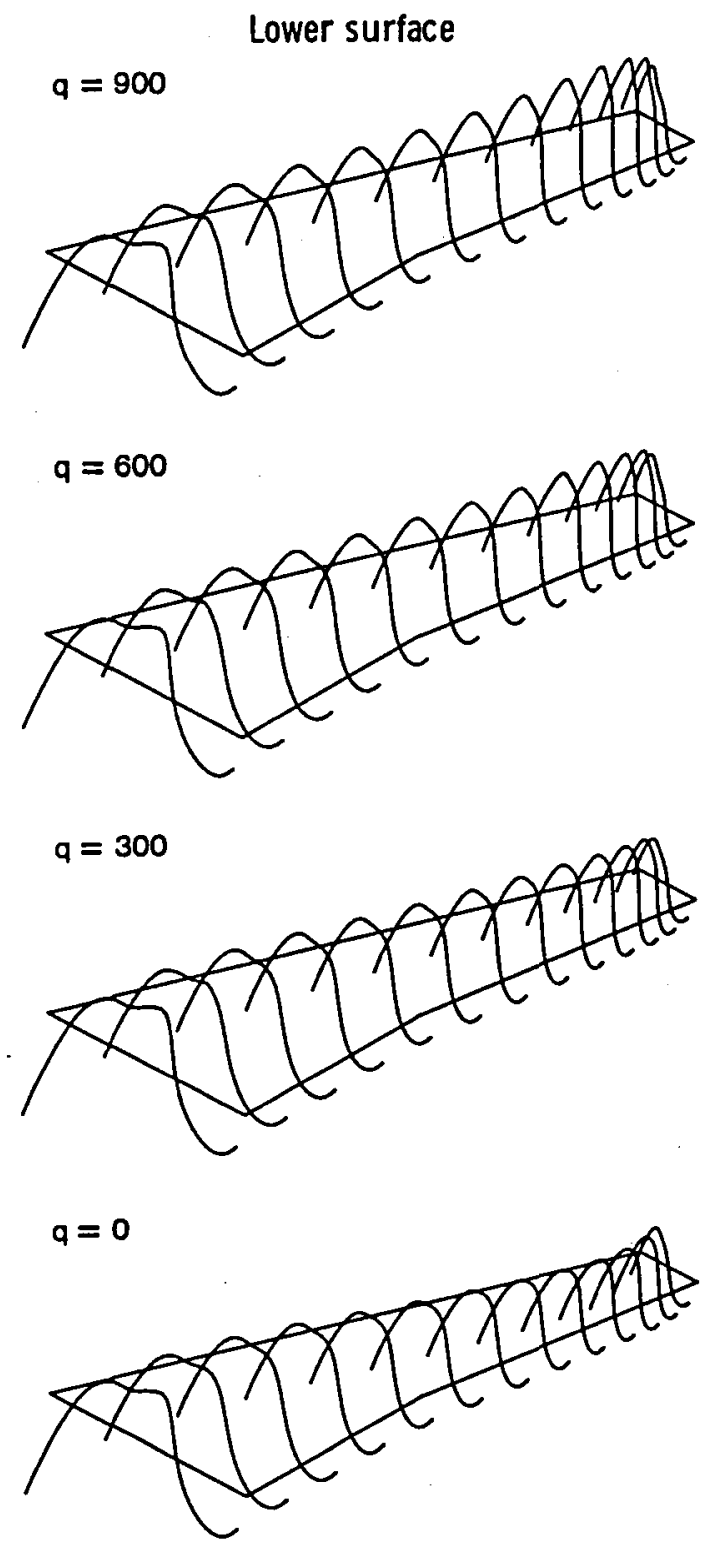

Fig 8 Static pressure distributions for flexible wing versus dynamic pressure, $M=0.8, \alpha=0^{\circ}$. 
Upper surface
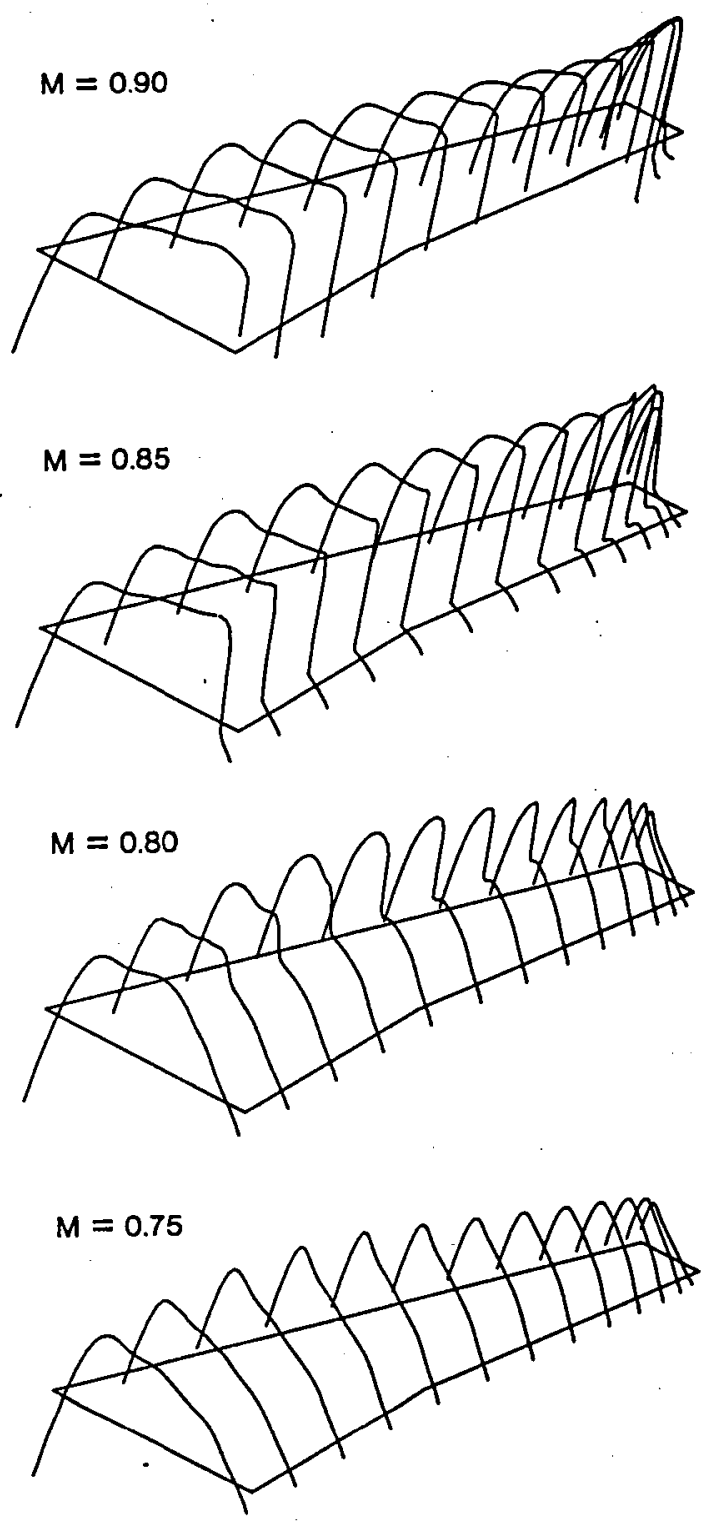

Lower surface
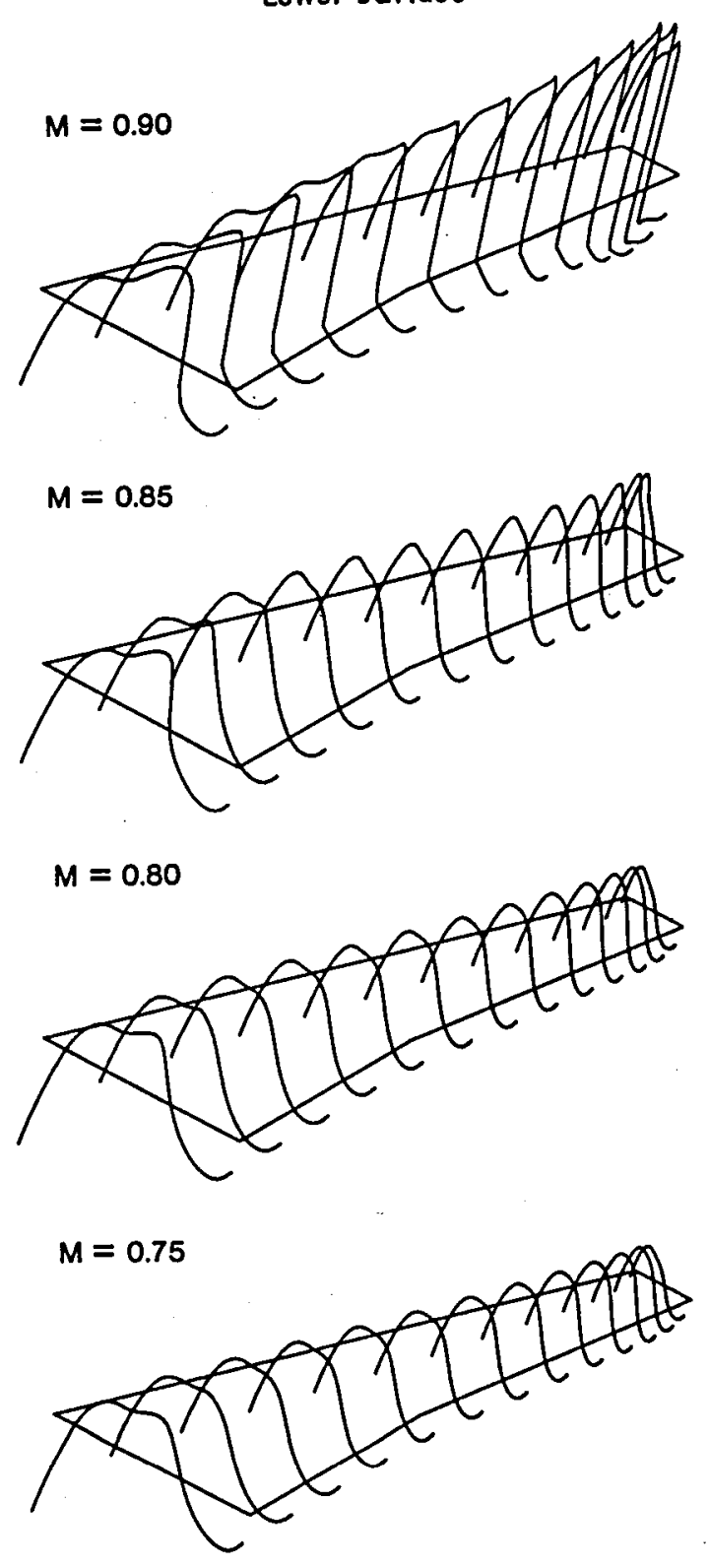

Fig. 9 Static pressure distributions for flexible wing versus Mach number, $q=300$ psf, $\alpha=0^{\circ}$. 


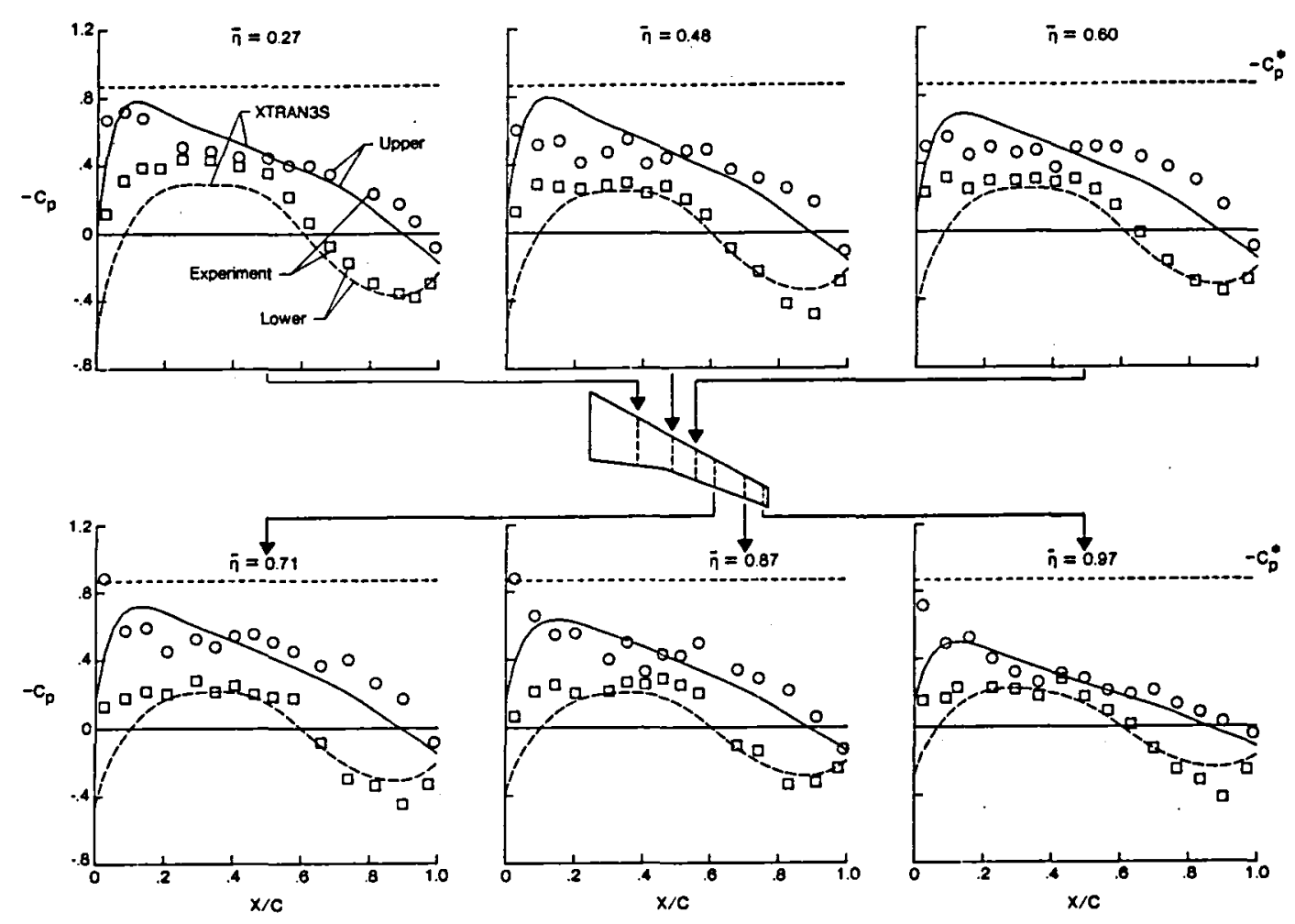

a) $M=0.70, q=200$ psf.
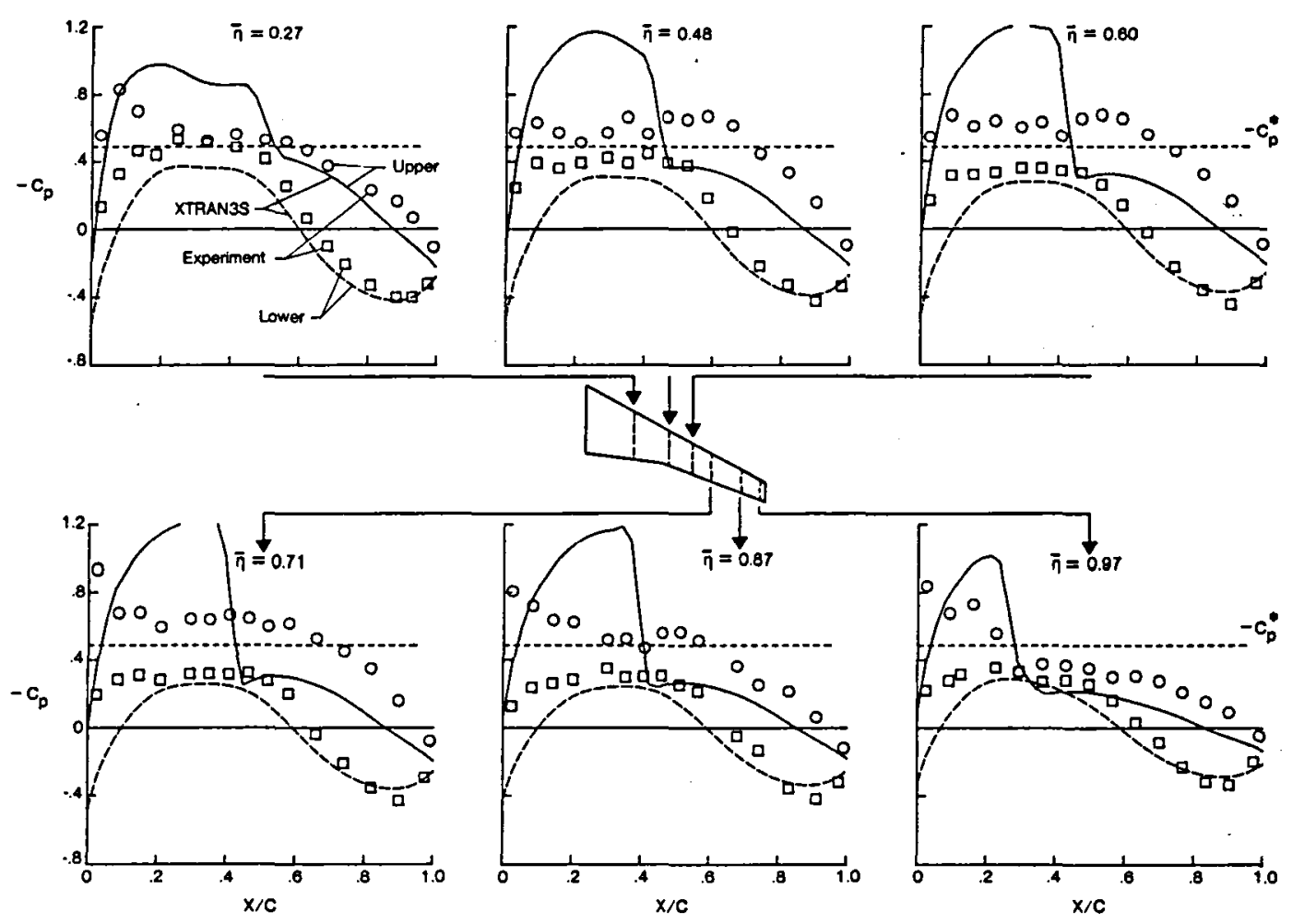

b) (continued) $M=0.80, q=100$ psf.

Fig. 10 Comparison of measured and calculated steady pressure distributions for the flexible wing, $a=0^{\circ}$. 


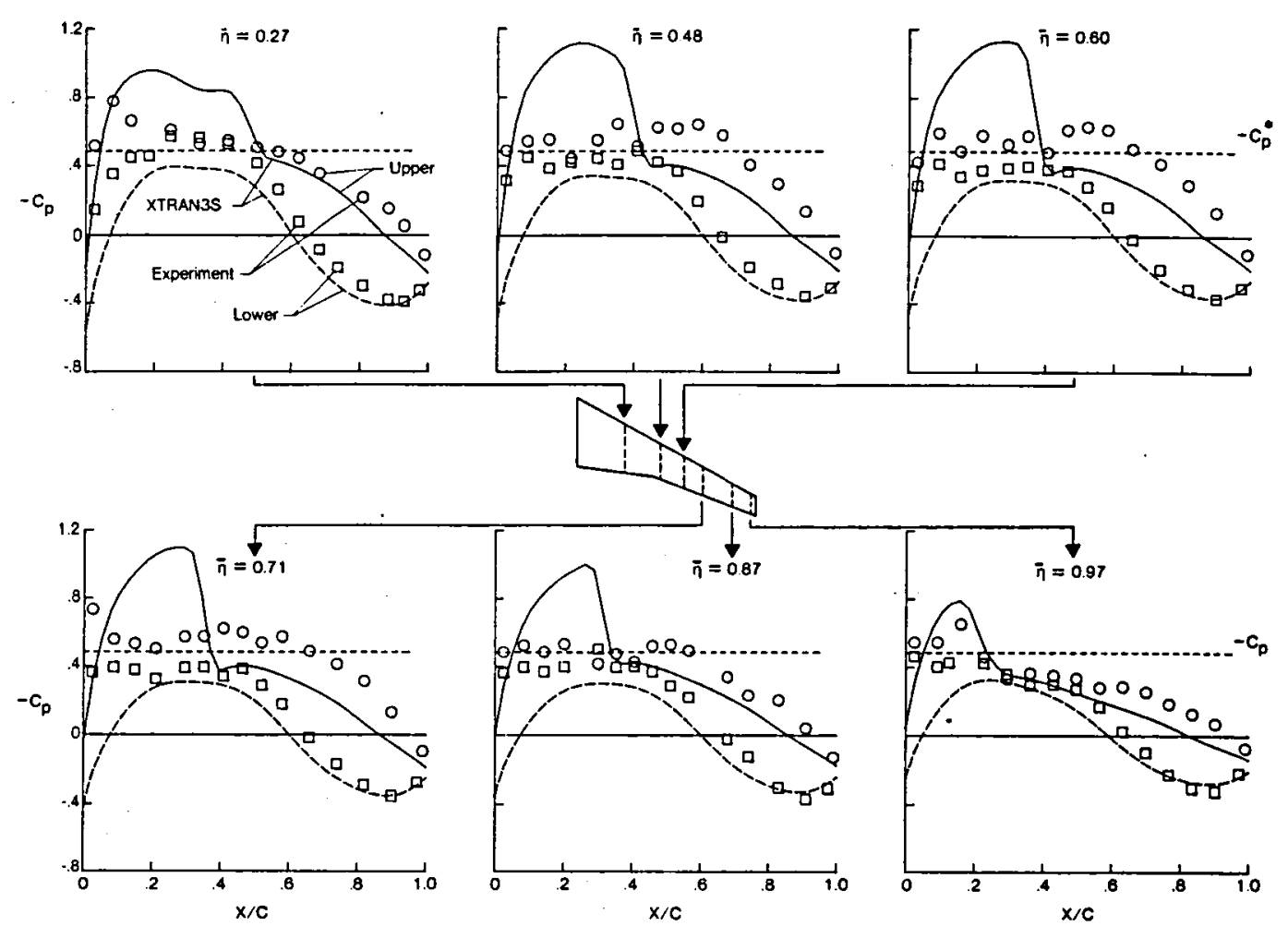

c) (continued) $M=0.80, q=200$ psf.
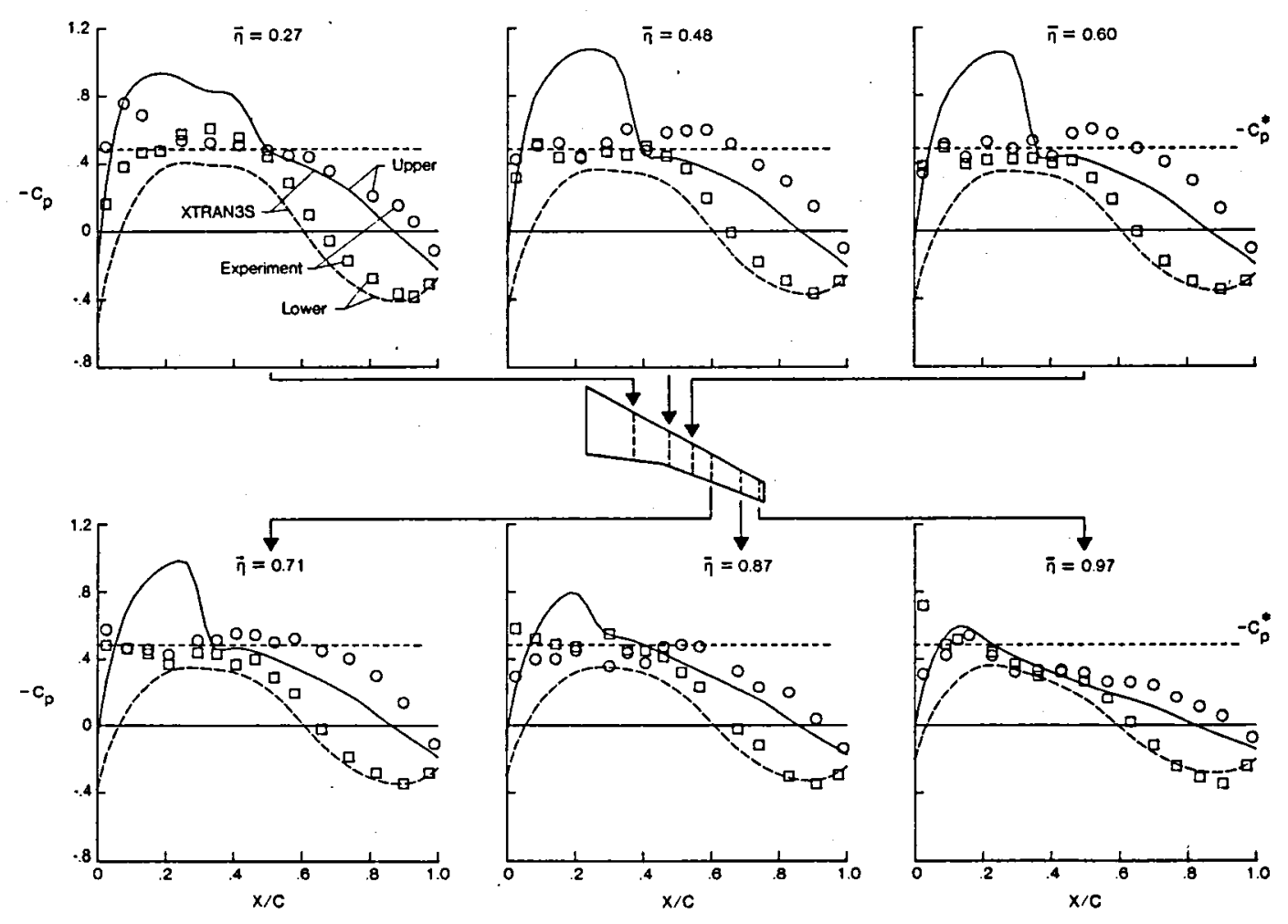

d) (continued) $M=0.80, q=300$ psf. 

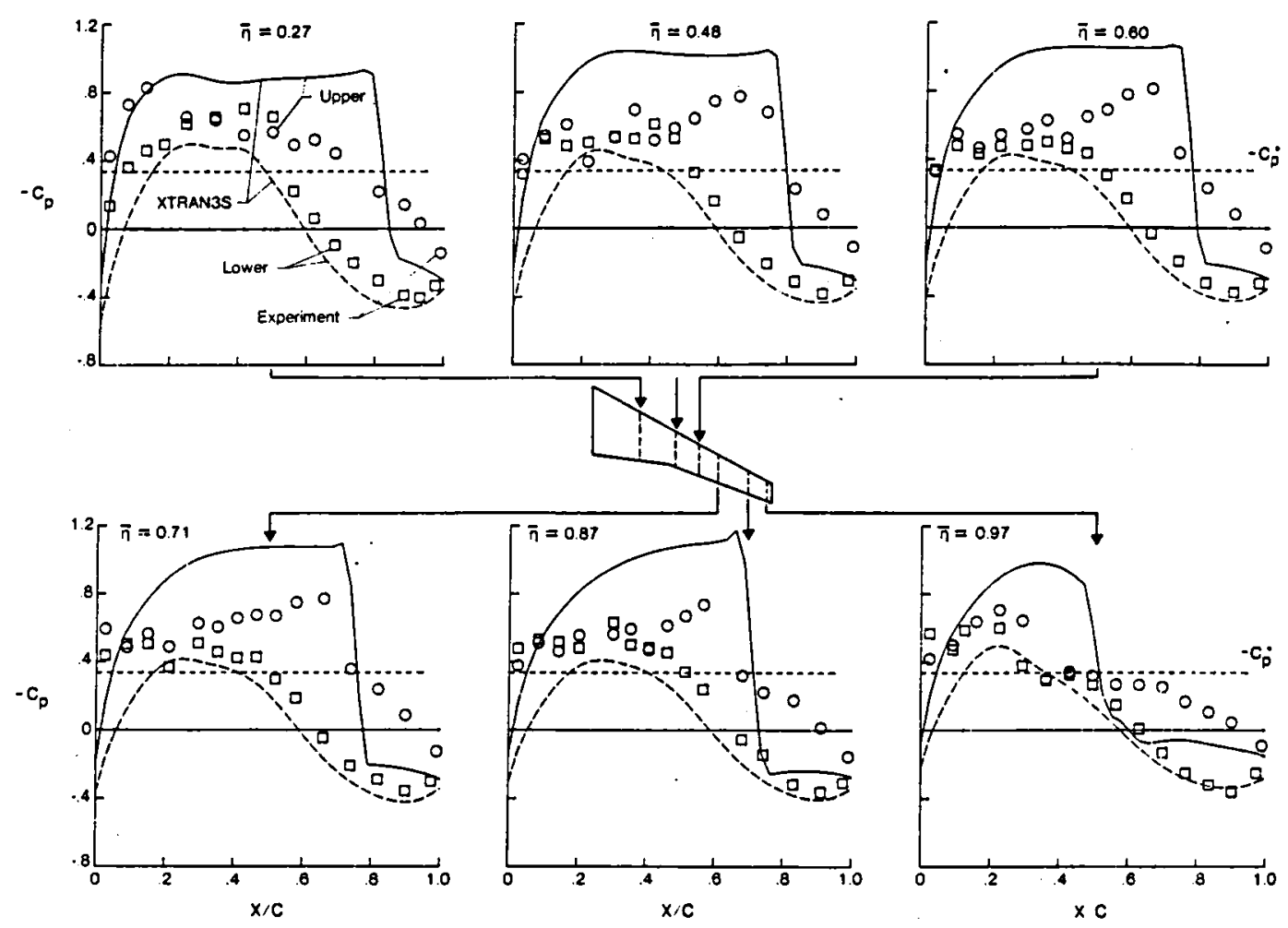

e) (concluded) $M=0.85, q=200$ psf.
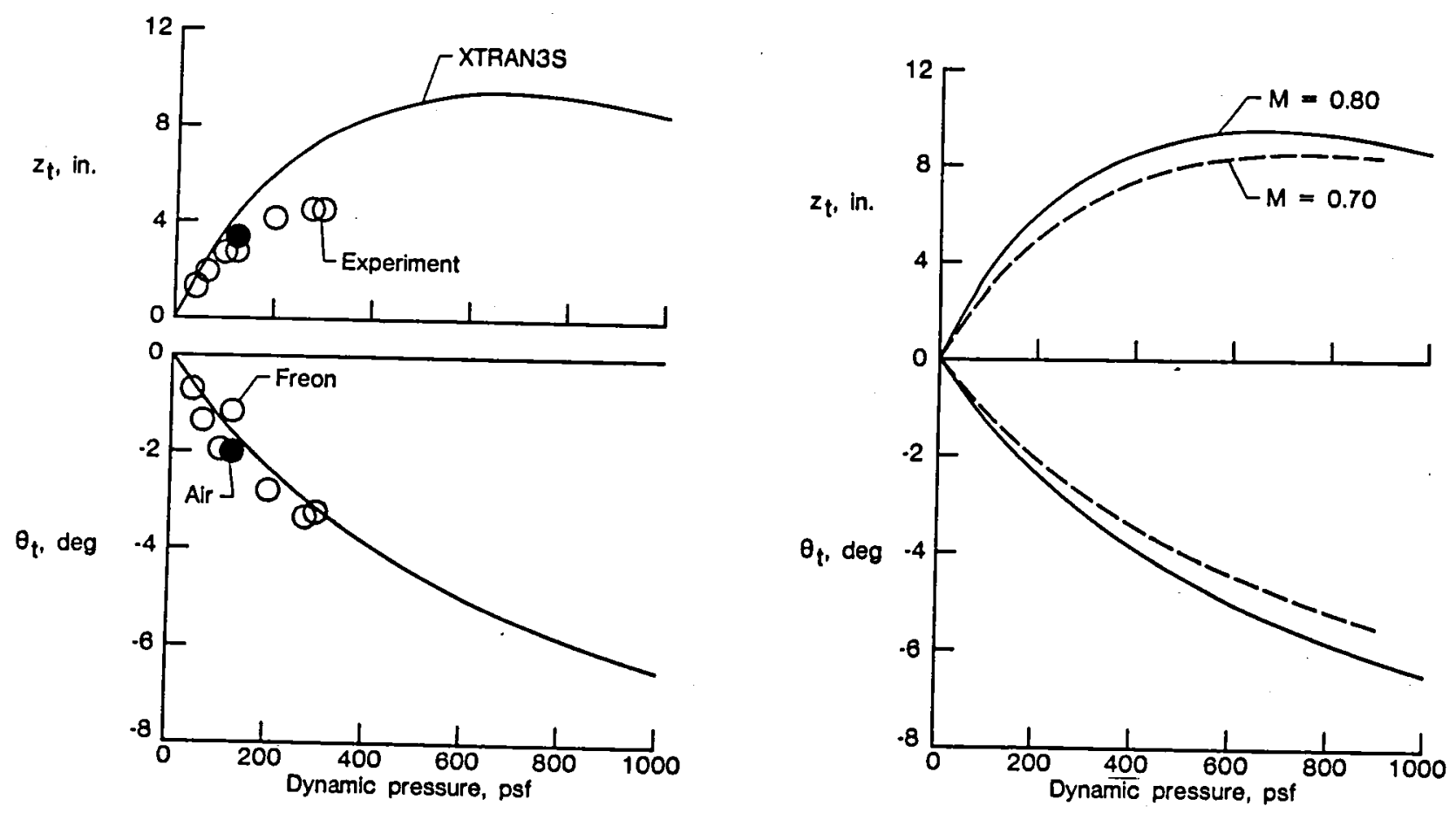

Fig. 11 Comparison of measured and calculated wing-tip displacement and twist versus dynamic pressure, $M=0.8, a=0^{\circ}$.

Fig. 12 Calculated wing-tip displacement and twist versus dynamic pressure, $\alpha=0^{\circ}$. 

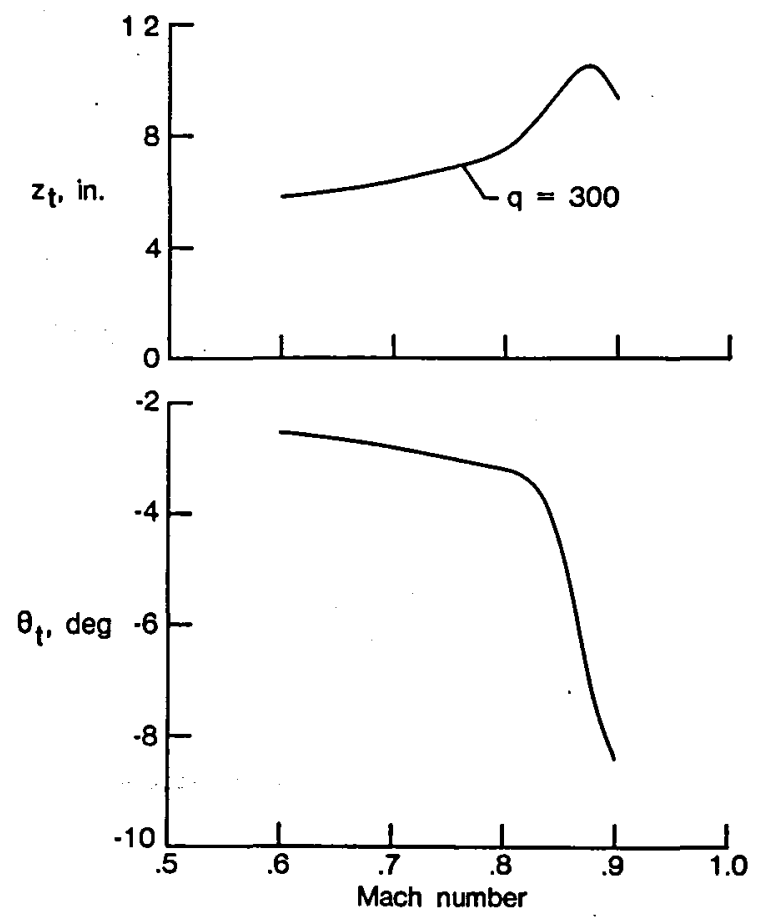

Fig. 13 Calculated wing-tip displacement and twist versus Mach number, $q=300$ psf, $\alpha=0^{\circ}$.
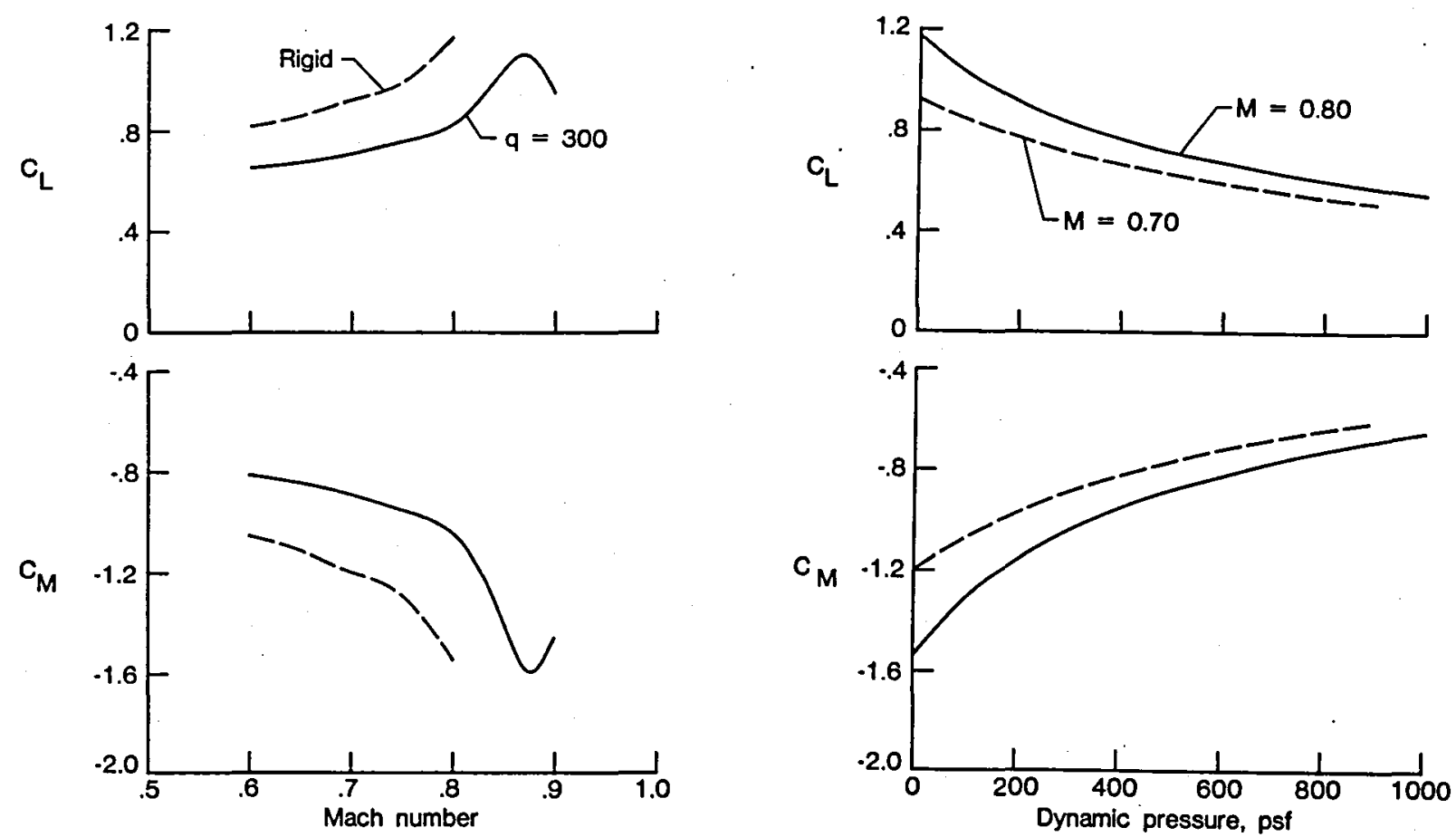

Fig. 14 Calculated wing 1 ift and pitching moment coefficients versus Mach number, $\alpha=0^{\circ}$.

Fig. 15 Calculated wing lift and pitching moment coefficients versus dynamic pressure, $\alpha=0^{\circ}$. 


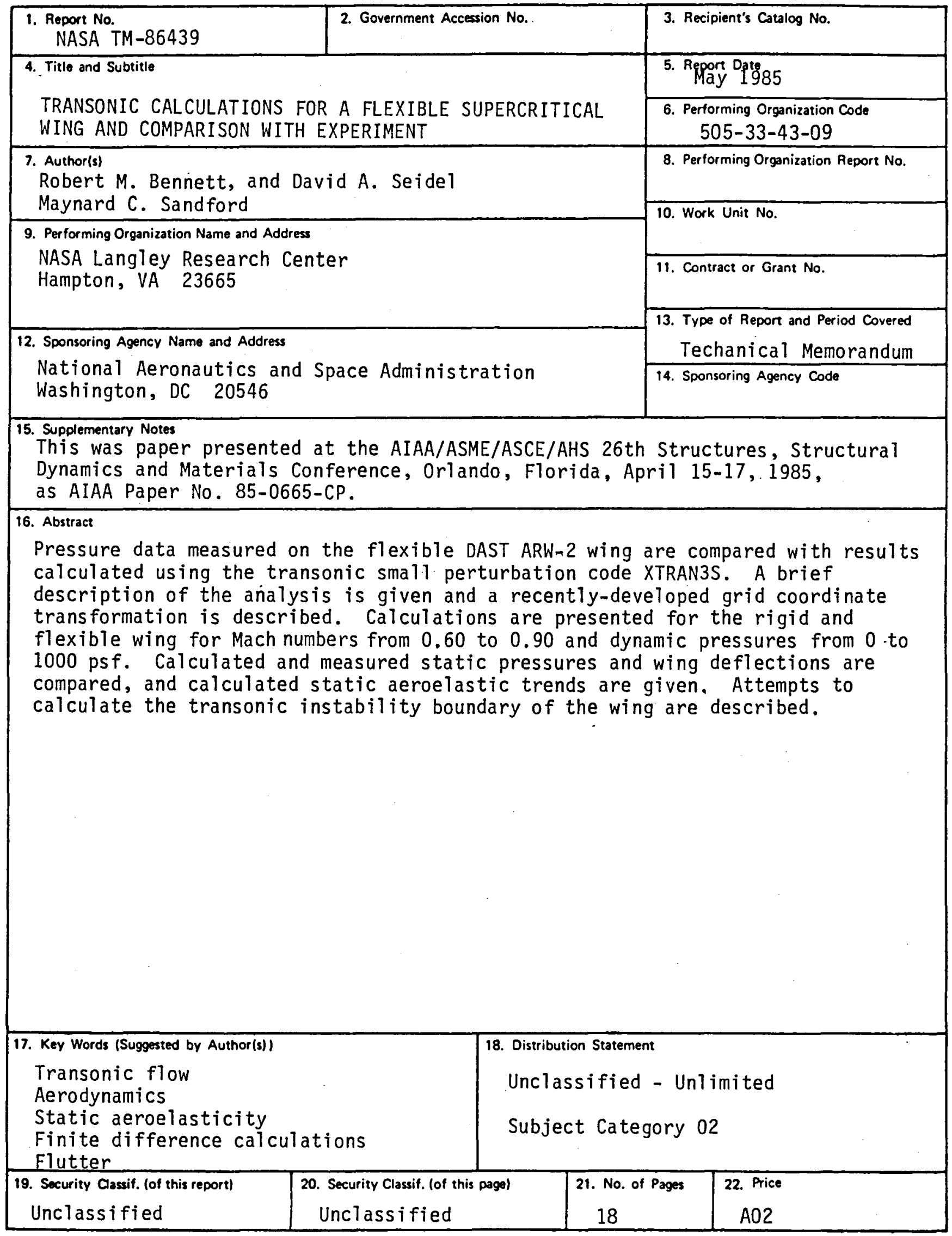


End of Document 